\title{
Perceptions of human resource professionals of challenges to and strategies for retaining managers
}

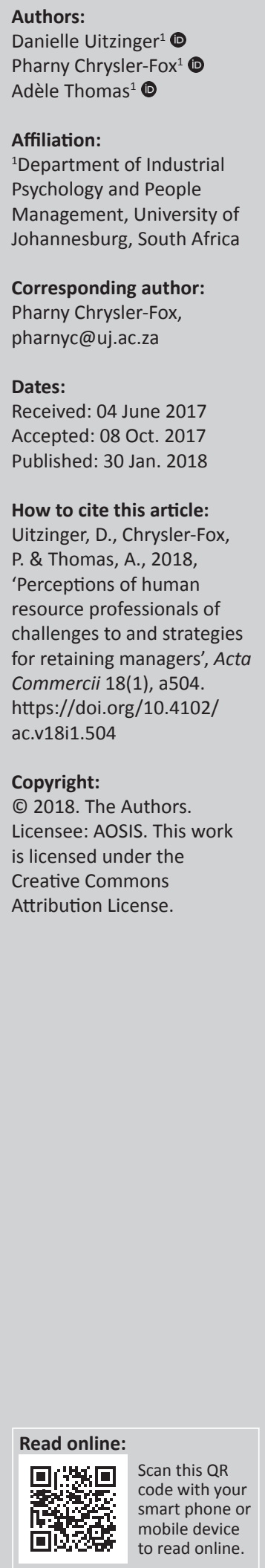

Orientation: Retaining and developing talented top- and middle-level managers who possess organisational-specific skills and experience promotes competitive advantage for organisations and is a long-term investment.

Research purpose: The purpose of this study was to explore challenges to retention and effective retention strategies for top- and middle-level managers.

Motivation for the study: Human resource (HR) managers are facing difficulties retaining managers as a result of ineffective retention strategies. This study aims to provide insight into suggested strategies to retain such managers.

Research design, approach and method: A cross-sectional survey, using an instrument developed from the literature, was completed by $97 \mathrm{HR}$ management professionals registered with the South African Board of People Practices. An exploratory factor analysis was conducted as well as group comparisons.

Main findings: Results revealed that leadership and performance management practices are considered to be effective retention strategies for top- and middle-level managers.

Practical and managerial implications: Having a deeper understanding of effective retention strategies for top- and middle-level managers can assist HR professionals in retaining these employees.

Contribution or value add: This study adds to the insights of HR professionals, line managers and leaders in organisations regarding retention challenges and effective retention strategies for top- and middle-level managers.

\section{Introduction}

Employee retention is one of the highest priorities in organisations, particularly with regard to top- and middle-level managers (Guthridge, Komm \& Lawson 2008). Employee retention is a long-term strategy that aims to identify talented employees and to develop and utilise these employees' talents to meet the growing demands of business (Hausknecht, Rodda \& Howard 2009). Talented employees are regarded as those who are highly skilled or who have firm-specific competencies and ones who make a substantial contribution to the intellectual capital of the organisation (Tymon, Stumpf \& Doh 2010). Employee retention is regarded as a strategic human resource (HR) practice as it involves long-term succession planning, forecasting strategic organisational needs and identifying, developing and retaining talented employees to fulfil future business requirements (Govaerts et al. 2011; Iles, Chuai \& Preece 2010). Organisations implement high-performance work systems in order to increase job satisfaction, increase organisational commitment and retain talented top- and middle-level managers (Boxall 2012). High-performance work systems are a set of HR practices that are designed to integrate with each other and work systematically with the organisation's systems to increase the performance of employees (Boxall 2012). High-performance work systems help to ensure that there is alignment between the organisation's strategies and goals and the HR practices that are implemented in the organisation (Boxall 2012).

Top-level managers provide strength to organisations as they have knowledge and firm-specific experience (Tarique \& Schuler 2010). They are also responsible for the strategic decision-making and planning for the organisation (Menz 2012). Middle-level managers are popularly regarded as being departmental heads and operational managers who interpret and convey information between the workforce and the leaders of the organisation (Monsen \& Boss 2009), especially regarding decisions that will impact the strategic direction of the organisation (Menz 2012). 
Both levels of management are considered to be valuable to organisations and turnover among them is recognised as being costly (Cosack, Guthridge \& Lawson 2010; Van Dyk \& Coetzee 2012), necessitating the urgency to retain such managers (Van Dyk \& Coetzee 2012). The Department of Higher Education and Training (2016) recently indicated that top-level managers (e.g. directors and chief information officers) and middle-level managers representing different functions of a business were among the occupations high in demand. South African organisations may not be successful in addressing this demand because of the ageing workforce, and the next cadre of young managers leaving South Africa. StatsSA (2016) reported that people aged between 25 and 29 years, in particular those from Gauteng, represented the biggest proportion of emigrants between 2011 and 2015 . Accordingly, the temptation may exist to utilise quick, extrinsic incentives (such as monetary rewards and benefits) to retain these talented people (Cosack et al. 2010). However, extrinsic incentives alone have been found not to decrease managerial turnover rates (Cosack et al. 2010).

HR professionals who are able to successfully implement effective employee retention strategies to retain managerial talent provide long-term benefits for organisational success over time, as well as contribute to the economic development and stability of South Africa (Govaerts et al. 2011; Van Dyk \& Coetzee 2012). Many organisations fail to review and develop new HR practices when the organisational strategies, goals and objectives, products and services and other main business priorities are updated (Guest \& Conway 2011).

\section{Objectives}

Allen and Bryant (2012) criticise current literature relating to employee retention as being too general, noting that while the literature explains what the problem is with regard to being unable to retain talented employees, it provides few practical recommendations to overcome this problem. The objectives of this study were (a) to identify challenges to retaining top- and middle-level managers and (b) to identify strategies to retain them as perceived by senior HR professionals. These objectives address the research problem of how to retain senior managers, which is critical to the economy of the country.

\section{Contribution to the field}

The present study seeks to provide insights into the perspectives of HR professionals into the challenges to and strategies for talent retention of top- and middle-level managers across various economic sectors in South Africa.

\section{Literature review}

The following section provides an overview of the challenges faced by organisations and HR professionals in retaining top talent, followed by a consideration of retention strategies.

\section{Challenges to retaining talent}

External environmental factors such as globalisation, sophisticated and continuously improving technology, access to worldwide information, and the evolution of multinational corporations have resulted in volatile, dynamic and open business environments (Cappelli 2008; Wagar \& Rondeau 2006). These changes have caused HR professionals to confront an increasing number of challenges in retaining senior staff (Cappelli 2008; Tarique \& Schuler 2010). The ease of international mobility has become a pull factor for managers (Farndale, Scullion \& Sparrow 2010), particularly in the case of highly skilled managers who have tertiary-level qualifications (Khoele \& Daya 2014). Guthridge and Komm (2008) report that top managers move, on average, twice to other countries to promote their career opportunities.

According to Monsen and Boss (2009) one of the main reasons for high employee turnover rates is a poor working environment. A poor working environment hinders employee engagement, reduces motivation levels and affects employees' overall performance (Devi 2009). Organisations that experience high turnover rates are often characterised by hierarchies and micromanagerial styles that decrease job satisfaction and present challenges to retaining talented employees (White 2010). Leaders who micromanage hinder their employees' development, decrease productivity and drive talented employees to leave by not allowing them discretion in conducting their work (White 2010).

Employees develop intentions to leave an organisation when they are required to perform work that is boring, unexciting and meaningless (Bhatnagar 2007; Doh et al. 2011), are subject to extreme workloads (Doh et al. 2011) and are set unrealistic performance goals (Monsen \& Boss 2009). If talented employees are not intellectually stimulated by their work, they may seek alternative employment that offers intellectual stimulation (Doh et al. 2011). Additionally, Govaerts et al. (2011) note that employees require evidence that their contributions impact the bottom line. Highly skilled employees are also more likely to stay with organisations that provide them with development and advancement opportunities (Devi 2009; Hausknecht et al. 2009).

Employees expect their leaders to acknowledge, understand, and in some cases, provide assistance to ensure their overall wellbeing (Ladyshewsky 2010). As a result of the increasing demands in the workplace and work-life conflict, employee wellness should be a strategic priority in all organisations (Deery 2008).

When employees believe that their wellbeing is a concern for the organisation, employee stress is reduced and organisational commitment is stimulated (Govaerts et al. 2011; Van Dyk \& Coetzee 2012). According to Tansley (2011), talented and highly skilled employees are attracted to wellness programmes and when organisations have welldeveloped and effective Employee Assistance Programmes, it communicates a message of concern to employees (Wagar \& 
Rondeau 2006). Neglecting employee wellness leads to employee turnover (Deery 2008; Yarnall 2011).

\section{Strategies to retain talent}

The effectiveness of HR practices, particularly employee retention strategies, is directly influenced by leaders (Lawler 2008). Letchmiah and Thomas (2017) recently found that leadership, organisational culture, organisational purpose, developmental opportunities, meaningful work and collegiality are factors to consider in retaining high-potential employees. The overt behaviour of leaders provides an insight into their attitudes towards their employees (Jaaskelainen 2011). Leaders should develop a clear and strong vision to increase job satisfaction and employee retention (Yarnall 2011). Committed employees become frustrated and develop turnover intention when they witness their work and input going to waste as a result of inconsistent strategies and visions (Döckel, Basson \& Coetzee 2006). Organisations that have a strong vision and mission are able to attract and retain talent because the vision communicates organisational purpose to employees (Hausknecht et al. 2009; Kim \& Lee 2007).

A high level of trust between employees and leaders is associated with high employee retention rates and employee commitment (Tansley 2011). Trust also underlies the concept of ethical leadership that is important for employee retention; increased employee turnover intention is caused by poor ethical leadership and unethical actions in organisations (Avey, Wernsing \& Palanski 2012; Kerr-Phillips \& Thomas 2009). Leaders should prioritise retention, provide executive support and appreciation, as well as model trusting and ethical behaviour (Avey et al. 2012).

Having and maintaining a strong organisational culture is imperative for retaining talented employees (Kerr-Phillips \& Thomas 2009; Tansley 2011). Organisational culture is a reflection of how employees perceive and feel about the organisation (Van Dyk \& Coetzee 2012), is developed over time and is seen as a long-term strategy that influences the dynamics of the organisation (Guthridge et al. 2008). Organisational culture influences employees' behaviour and attitudes towards organisational commitment (Guthridge et al. 2008).

An organisation's culture can also contributes to talent management architecture, as when HR professionals, together with the leaders of an organisation, consistently place emphasis on the concept of talent management, it embeds a mindset of talent management within the organisational culture (Ashton \& Morton 2005; Guthridge et al. 2008). It has been recommended, particularly in South Africa, that HR professionals should focus on creating a culture that accommodates and supports the diversity of the workforce in order for employees to feel a sense of acceptance and belonging and to avoid feelings of isolation (Edwards \& Cable 2009; Kerr-Phillips \& Thomas 2009). A culture that embraces employees helps to create a sense of organisational identification that complements employee retention strategies (Edwards \& Cable 2009).

Organisations that have low employee turnover levels tend to implement a soft approach to HR (Jaaskelainen 2011) that involves treating employees as valuable resources and building engagement in the organisation (Tansley 2011). Leaders and managers who build engagement promote a high level of trust, communication and understanding between themselves and their employees (Iles et al. 2010). Organisational behaviour practices include personality assessments and personality fits, learning and development, applied motivational practices and employee wellness programmes, which are found to increase the skills of managers as well as assist HR professionals in the identification of managerial talent (McDonnell et al. 2010). The individual attention received by each employee as a result of organisational behaviour practices also stimulates organisational commitment and reduces turnover intention of talented employees (Iles et al. 2010).

The key to retaining talented and high potential employees is to consistently implement effective employee engagement practices (Bhatnagar 2007; Devi 2009). Employee engagement practices allow employees to become familiar with the organisation and organisational procedures (Iles et al. 2010) and contribute to employee involvement and networking (Bhatnagar 2007; Devi 2009). Effective employee engagement activities have been found to stimulate employee retention rates (Doh et al. 2011; Tarique \& Schuler 2010). Employee engagement has also been found to become increasingly important in organisations with diverse workforces as it allows employees to get to know one another and appreciate the diversity inherent in the organisation (McDonnell et al. 2010).

Performance management is the formal and systematic communication between managers and employees regarding behavioural expectations, objectives and goals, and ensures that feedback is provided to employees relating to their performance (Doh et al. 2011; Edwards \& Cable 2009). Performance management, as a relevant HR practice, should not operate in isolation, but should supplement talent management by ensuring that regular cyclical results of employee performance are documented (Bhatnagar 2007).

As an employee retention strategy, managers are often given the opportunity to work with HR professionals and senior managers of the organisation to understand managerial expectations, the long-term objectives of the organisation and targets set by the organisation (Doh et al. 2011; Edwards \& Cable 2009). This practice of performance management develops, in managers, an appreciation of what is demanded of them and their teams that, in turn, contributes to feelings of job autonomy (Doh et al. 2011; Lawler 2008). Performance management activities that are implemented fairly, consistently and transparently tend to increase the level of trust between top- and middle-level managers of the organisation (Doh et al. 2011). 
Reward management, closely associated to performance management, is also utilised as a strategy to retain managerial talent (Tansley 2011). However, the rewards offered to employees must be tailored to suit and satisfy topand middle-level managers (Bhatnagar 2007; Cosack et al. 2010). While not completely excluding extrinsic rewards, employees at managerial levels generally prefer intrinsic rewards that promote self-fulfilment (Doh et al. 2011; Hausknecht et al. 2009).

When rewards match the desires of managers, which may differ at each level, it enhances the psychological contract, stimulates commitment, reduces turnover intention and retains the managerial talent (Avey et al. 2012; Wagar \& Rondeau 2006). Furthermore, customising intrinsic rewards for managers is known to promote retention (Tymon et al. 2010).

Development is another key HR practice that plays a role in retaining talented employees (McDonnell et al. 2010; Van Dyk \& Coetzee 2012). Development programmes aid in improving individual and organisational performance, as well as contribute to the personal growth and self-mastery of employees (Doh et al. 2011; McDonnell et al. 2010). Development programmes help employees address changes in the external environment (Govaerts et al. 2011; Tarique \& Schuler 2010) and contribute to employee awareness and knowledge of the future and of job security (Govaerts et al. 2011; Tarique \& Schuler 2010). Recognition for achieving developmental goals, closely associated with career advancement, may address turnover when combined with skills-based pay (Allen \& Bryant 2012).

\section{Research method and design}

This section addresses the research approach and method followed.

\section{Research approach}

A quantitative approach was followed and a cross-sectional field survey was conducted based on an instrument that evolved from the literature review. This study was exploratory-descriptive (Marshall \& Rossman 1999) as the literature is sparse that deals with the differences between top- and middle-level managers.

\section{Research method}

The research method details the nature of the respondents, the measuring instrument used, the research procedure adopted as well as the statistical analyses employed.

\section{Respondents}

A non-probability targeted sampling technique (Gelo, Braakmann \& Benetka 2008) was employed to sample during February 2016 HR professionals registered with the South African Board of People Practices (SABPP) $(N=3132)$ in the categories of HR Professionals, Chartered HR Professionals and Master HR Professionals. The number of respondents $(n=97)$ included: 44 HR Professionals (Degree +3 years' experience), 43 Chartered HR Professionals (Honours degree +4 years' experience) and 10 Master HR Professionals (Master's and doctorate degree +6 years' experience). The majority of professionals $(n=63)$ were responsible for talent management, more specifically $70 \%$ of Master HR Professionals, followed by $69.8 \%$ of Chartered HR Professionals and $41.4 \%$ of HR Professionals. Over $46.0 \%$ of the companies in the sample employed more than 1000 people. Almost $30.0 \%$ of companies employed between 101 and 500 people.

\section{Measuring instrument}

A self-administered questionnaire was developed to measure retention challenges and strategies identified by $\mathrm{HR}$ professionals. An attempt was made to formulate a manageable questionnaire in terms of length and the researchers could not find any existing questionnaires that dealt with challenges of retaining managers.

Two subscales were developed to measure retention challenges. The subscale relating to organisational context consisted of seven items, examples being 'affirmative action policies' and 'traditional hierarchies'. The subscale relating to job context consisted of 10 items, examples being 'lack of challenging work' and 'increase in workload'.

Three subscales were developed to measure retention strategies. The subscale relating to leadership consisted of seven items, examples being 'trust between line managers and direct reports' and 'communication between line managers and direct reports'. The subscale relating to performance management was measured with seven items (e.g., 'recognition for achieving developmental goals' and 'line managers collaboratively set targets with direct reports'). Employee wellbeing was measured by means of a subscale comprising four items, for example 'lack of concern from line managers for personal welfare' (reverse scored) and 'lack of assistance from the HR department to help deal with personal problems' (reverse scored). The 35 questions were answered on a five-point Likert scale. All items required participants to select a response each for top-level and middle-level managers ranging from 1 ('not probable') to 5 ('very probable').

\section{Strategy to ensure quality of the instrument}

A pilot study was conducted with two HR professionals and five academics in the HR field before the online questionnaire went live. Feedback was recorded and the suggested changes involved the rephrasing of four questions to ensure that they could be better understood.

\section{Research procedure}

\section{Data collection}

Permission was obtained from the SABPP to access its registered members. The questionnaire was electronically 
distributed to respondents by the SABPP. A covering letter explained why these SABPP members had been selected and provided a link which directed respondents to the online survey. The introductory letter provided a brief background to the study, explained the purpose of the study, noted that participation was voluntary, that information provided would be kept confidential and that respondents could withdraw at any time. Informed consent was sought from respondents. Respondents remained anonymous and data were stored in a secure and confidential manner.

\section{Statistical analyses}

Exploratory factor analysis (EFA) and reliability analysis were conducted. This was followed by a KolmogorovSmirnov test to ascertain normality, and a paired-samples $t$-test for the group comparisons between top- and middlelevel managers. Cohen's (1988) guidelines were used to interpret effect sizes. All analyses were conducted using SPSS Version 23 (IBM Corp. 2015).

\section{Results}

The overall objectives of the study were to explore challenges to retaining and strategies to retain top- and middle-level managers in South African organisations.

\section{Dimensionality of retention challenges and strategies}

\section{First-order exploratory factor analysis}

A first-order EFA was conducted on all questionnaire items to identify the latent constructs of newly created measures that represent retention challenges and strategies (Bandalos \& Finney 2010). The items were initially examined for factorability. One item, 'lack of assistance from colleagues when experiencing personal problems', with a weak correlation coefficient value (measure of sampling adequacy [MSA] $=0.576$ ) below 0.600 (Tabachnick \& Fidell 2014), was excluded from further factor analyses. Several correlations exceeded 0.300. The Kaiser-Meyer-Olkin measure of sampling adequacy was 0.746 , above the cut-off value of 0.600 (Tabachnick \& Fidell 2014) and Bartlett's Test of Sphericity was significant $\left.\left.\left(\chi^{2}\right)-595\right)=1674.791, p<0.001\right)$.

Based on the above indicators for factorability, the EFA was conducted on the 34 items. Principle axis factoring was used to extract a linear group of variables that explain the maximum amount of variance in cases of more than 30 variables (Abdi \& Williams 2010). Varimax rotation was employed to minimise the complexity of the factors (Tabachnick \& Fidell 2014). Eight factors, with eigenvalues above 1 (Tabachnick \& Fidell 2014), were extracted explaining a cumulative variance of $71 \%$. This solution was not parsimonious; for example, only one item loaded on Factor 8 . In the following rounds, a total of 11 items were removed because of low communality estimates $(<0.030)$ (Bandalos \& Finney 2010) and cross-loadings $>0.300$ (Tabachnick \& Fidell 2014), resulting in non-parsimonious factor structures. Four items were dropped from organisational context, for example 'international mobility' and 'external job offers'; six items were dropped from job context with examples being 'unrealistic goals set by leaders' and 'lack of career growth or promotions'. One item, 'retention of managers is a strategic priority for the executives of the organisation', was excluded from the subscale leadership.

The final EFA was conducted on 23 items and forced into a five-factor solution as one item loaded on one factor in a six-factor solution. Assumptions for factorability were met; sizeable correlations on the correlation matrix were above 0.300 , the Kaiser-Meyer-Olkin measure of sampling adequacy was 0.760 , above the cut-off value of 0.600 (Tabachnick \& Fidell 2014) and Bartlett's Test of Sphericity was significant $\left(\chi^{2}(253)=1076.480, p<0.001\right)$. The Kaiser normalisation rotation converged in six iterations. Five factors, with eigenvalues greater than 1 and explaining $67.75 \%$ of the variance, were extracted. A summary of the pattern coefficients, eigenvalues, communality estimates and reliability estimates Cronbach's alpha values for the final solution are presented in Table 1. All items had primary loadings above 0.50 , with the majority of items above 0.71 , which is considered excellent (Tabachnick \& Fidell 2014).

The theoretical labels were retained for the final factor labels (presented in Table 1): Factor 1 (performance management), Factor 2 (leadership), Factor 3 (employee wellbeing), Factor 4 (work environment) and Factor 5 (organisational context).

Performance management comprised items that related to line managers collaboratively setting reasonable targets with direct reports and rewarding them for meeting targets, in particular through meaningful rewards that suit the preferences of direct reports. This factor also included development that includes the quality of developmental or training opportunities as well as collaboration between line managers and direct reports to determine developmental needs and to provide recognition for the achievement of developmental goals.

Leadership comprised items relating to trust and communication between line managers and direct reports, as well as appreciation and support by line managers to direct reports. Leadership style and ethical leadership also formed components of this factor.

Employee wellbeing included a concern for employees' personal welfare by both HR and line managers, as well as assistance from the HR department in helping employees deal with personal problems.

Within the work environment factor, the following were incorporated: a lack of employment engagement and a lack of workforce diversity in the organisation and, more specific 
TABLE 1: Factor loadings for Varimax with Kaiser Normalisation five-factor solution.

\begin{tabular}{|c|c|c|c|c|c|c|}
\hline Factors and items & Factor 1 & Factor 2 & Factor 3 & Factor 4 & Factor 5 & Com. $^{+}$ \\
\hline \multicolumn{7}{|l|}{ Factor 1: Performance management $(\alpha=0.900)$} \\
\hline 5.7 Recognition for achieving developmental goals & 0.768 & - & - & - & - & 0.691 \\
\hline 5.6 Quality of developmental or training opportunities & 0.767 & - & - & - & - & 0.642 \\
\hline 5.2 Setting reasonable targets & 0.766 & - & - & - & - & 0.678 \\
\hline 5.4 Meaningful rewards to suit the preferences of direct reports & 0.749 & - & - & - & - & 0.613 \\
\hline 5.5 Line managers collaboratively determine developmental needs with direct reports & 0.734 & - & - & - & - & 0.651 \\
\hline 5.1 Line managers collaboratively set targets with direct reports & 0.703 & - & - & - & - & 0.542 \\
\hline 5.3 Rewards for meeting targets & 0.616 & - & - & - & - & 0.476 \\
\hline \multicolumn{7}{|l|}{ Factor 2: Leadership $(\alpha=0.904)$} \\
\hline 4.5 Trust between line managers and direct reports & - & 0.833 & - & - & - & 0.740 \\
\hline 4.3 Executive appreciation by line managers & - & 0.761 & - & - & - & 0.652 \\
\hline 4.6 Communication between line managers and direct reports & - & 0.758 & - & - & - & 0.638 \\
\hline 4.4 Leadership style of line managers & - & 0.731 & - & - & - & 0.567 \\
\hline 4.2 Executive support by line managers & - & 0.720 & - & - & - & 0.627 \\
\hline \multicolumn{7}{|l|}{ Factor 3: Employee wellbeing ( $\alpha=0.847$ ) } \\
\hline 6.3 Lack of assistance from the HR department in helping to deal with personal problems $(\mathrm{R})^{\mathrm{b}}$ & - & - & 0.803 & - & - & 0.745 \\
\hline 6.2 Lack of concern by HR managers for personal welfare $(R)^{\ddagger}$ & - & - & 0.793 & - & - & 0.746 \\
\hline 6.1 Lack of concern by line managers for personal welfare $(R)^{\ddagger}$ & - & - & 0.725 & - & - & 0.661 \\
\hline \multicolumn{7}{|l|}{ Factor 4: Work environment ( $\alpha=0.736)$} \\
\hline 3.10 Lack of employment engagement & - & - & - & 0.812 & - & 0.713 \\
\hline 3.9 Lack of workforce diversity & - & - & - & 0.640 & - & 0.457 \\
\hline 3.3 Increase in workload & - & - & - & 0.541 & - & 0.366 \\
\hline 3.2 Lack of challenging work & - & - & - & 0.500 & - & 0.415 \\
\hline \multicolumn{7}{|l|}{ Factor 5: Organisational context $(\alpha=0.691)$} \\
\hline 1.3 Outdated technology & - & - & - & - & 0.709 & 0.579 \\
\hline 1.4 Traditional hierarchies & - & - & - & - & 0.669 & 0.537 \\
\hline 1.5 Affirmative action policies & - & - & - & - & 0.551 & 0.394 \\
\hline \multicolumn{7}{|l|}{ Total variance explained } \\
\hline Cumulative percent of variance & 30.24 & 43.91 & 55.02 & 61.88 & 67.75 & - \\
\hline
\end{tabular}

Source: Authors' own work

Coefficients above 0.300 are shown in bold.

+ , Communalities.

$\ddagger$ Reversed-scored items.

to the individual employee, an increase in workload and lack of challenging work.

The last factor, organisational context, referred to the existence of outdated technologies, traditional hierarchies and affirmative action policies. The descriptive statistics for both managerial levels are reported in Table 3 to be discussed later.

Internal consistency, examined using Cronbach's alpha, was considered to be reliable for the five factors, with four factors having acceptable to excellent internal consistency estimates ranging between $\alpha=0.736$ and $\alpha=0.904$ (Nunnally 1978). Only Factor 5 (organisational context) attained the lowest reliability score $(\alpha=0.691)$ that could not be improved by removing items.

\section{Second-order exploratory factor analysis}

A second- or higher-order EFA was conducted to assess whether the factors extracted during the first-order EFA can be viewed as challenges and retention strategies (Cook \& Thomson 2000). This EFA generated factor correlations from the first-order analysis (Wind, Green \& Jain 1973). The KaiserMeyer-Olkin measure of sampling adequacy was 0.608 and is considered to be an adequate score for a second EFA
TABLE 2: Second-order factor loadings for Oblimin with Kaiser Normalisation two-factor solution.

\begin{tabular}{lcc}
\hline First-order factors & Factor $\mathbf{1}$ & Factor 2 \\
\hline Factor 1: Retention strategies $(\boldsymbol{\alpha}=\mathbf{0 . 7 9 7})$ & & - \\
$\quad$ Factor 1: Performance management & $\mathbf{0 . 6 9 6}$ & - \\
$\quad$ Factor 2: Leadership & $\mathbf{0 . 5 8 2}$ & -0.409 \\
$\quad$ Factor 3: Employee wellbeing & $-\mathbf{0 . 4 5 6}$ & \\
Factor 2: Retention challenges $(\boldsymbol{\alpha}=\mathbf{0 . 7 4 8 )}$ & & $\mathbf{0 . 6 1 4}$ \\
$\quad$ Factor 5: Organisational context & - & $\mathbf{0 . 6 0 9}$ \\
Factor 4: Work environment & - & \\
Total variance explained & & 1.215 \\
$\quad$ Eigenvalue & 2.047 & 24.047 \\
$\quad$ Percent of variance & 40.932 & 65.228 \\
$\quad$ Cumulative percent of variance & 40.932 & \\
Factor correlations & & 0.263 \\
$\quad$ Factor 1: Retention strategies & 1.000 & 1.000 \\
$\quad$ Factor 2: Retention challenges & 0.263 & \\
\hline
\end{tabular}

Source: Authors' own work

Coefficients above 0.300 are shown in bold.

(Williams, Brown \& Onsman 2012). Bartlett's Test of Sphericity was significant $\left(\chi^{2}(10)=70.755, p<0.001\right)$.

The structure coefficients, factor correlations and reliability estimates are presented in Table 2. Two factors with 
TABLE 3: Differences in the retention strategies and challenges between top- and middle-level managers.

\begin{tabular}{|c|c|c|c|c|c|c|c|c|c|}
\hline \multirow[t]{2}{*}{ Factor } & \multirow[t]{2}{*}{$n$} & \multicolumn{2}{|c|}{ Top-level managers } & \multicolumn{2}{|c|}{ Middle-level managers } & \multirow[t]{2}{*}{$t$} & \multirow[t]{2}{*}{$d f$} & \multirow[t]{2}{*}{ Sig. } & \multirow[t]{2}{*}{ Effect size $\left(\eta^{2}\right)$} \\
\hline & & Mean & $S D$ & Mean & $S D$ & & & & \\
\hline \multicolumn{10}{|l|}{ Retention challenges: } \\
\hline Employee wellbeing & 96 & 2.711 & 1.066 & 3.479 & 1.072 & -3.077 & 95 & $0.003 *$ & 0.09 \\
\hline Work environment & 95 & 3.203 & 0.943 & 3.549 & 0.797 & -5.422 & 94 & $0.000 * *$ & 0.24 \\
\hline Organisational context & 91 & 3.245 & 1.062 & 3.568 & 0.987 & -3.908 & 90 & $0.000 * *$ & 0.15 \\
\hline \multicolumn{10}{|l|}{ Retention strategies: } \\
\hline Leadership & 96 & 3.984 & 0.905 & 4.154 & 0.729 & -3.077 & 95 & $0.003 *$ & 0.09 \\
\hline
\end{tabular}

Source: Authors' own work

$n$, number; $S D$, standard deviation; $d f$, degrees of freedom.

$*, p<0.050 ; * *, p<0.001$.

eigenvalues greater than 1 were considered valid factors (Tabachnick \& Fidell 2014). These two factors explain 65.2\% of the variance. The Oblimin with Kaiser Normalisation method was used as a rotation method as it does not require orthogonality between factors, meaning that the values of the factors are independent of one another (Beaumont 2012). This rotation method reached convergence after seven iterations (or rotations). Factor 1 was labelled 'retention strategies' comprising performance management, leadership and employee wellbeing. Factor 2 was considered to relate to retention challenges and comprised 'the organisational context' and 'the work environment'. The Cronbach's alpha coefficients for retention strategies and retention challenges had acceptable internal consistency estimates $(\alpha \geq 0.70)$ (Nunnally 1978). Factor 1 (retention strategies) poorly correlated (0.263) with Factor 2 (challenges to retention).

\section{Differences between managerial levels}

Group comparisons were conducted between the managerial levels.

A Kolmogorov-Smirnov test was conducted as there were more than 50 respondents per group (Razali \& Wah 2011) and revealed that the data were normally distributed. Subsequently, a paired-samples $t$-test was considered to be appropriate as the sample size was big enough (Ramsey \& Schafer 2013). Results from a series of paired-samples $t$-tests and descriptive statistics are provided in Table 3.

Retention challenges: A series of paired-samples $t$-tests evidenced statistically significant differences for all retention challenges, in particular the probabilities, as indicated by HR professionals, to contribute to turnover among middle-level managers. The work environment was also more likely to contribute to turnover among middle-level managers $(M=3.549, S D=0.797)$ than among top-level managers $(M=3.203, S D=0.943)(t(94)=-5.422, p<0.001)$, with a large effect size $\left(\eta^{2}=0.24\right)$. Similarly, the organisational context is also more likely to negatively impact middle-level managers $(M=3.568, S D=0.987)$ than top-level managers $(M=3.245$, $S D=1.062)(t(90)=-3.908, p<0.001)$, with a large effect size $\left(\eta^{2}=0.15\right)$.
Retention strategies: Paired-samples t-tests revealed two statistically significant differences between the managerial levels. Performance management was deemed more likely by HR professionals to retain middle-level managers $(M=4.104$, $S D=0.774)$ than top-level managers $(M=4.018, S D=0.822)$ $(t(94)=-2.084, p=0.040)$, with a small effect size $\left(\eta^{2}=0.04\right)$. Similarly, leadership was regarded more likely to retain middle-level managers $(M=4.154, S D=0.729)$ than top-level managers $(M=3.984, S D=0.905)(t(95)=-3.077, p=0.003)$, with a moderate effect size $\left(\eta^{2}=0.09\right)$. A lack of care for employee wellbeing was more likely to contribute to turnover of middle-level managers $(M=3.479, S D=1.072)$ than to the turnover of top-level managers $(M=2.711, S D=1.066)$ $(t(95)=-3.077, p=0.003)$, with a moderate effect size $\left(\eta^{2}=0.09\right)$.

\section{Discussion}

The overall objectives of the study were (a) to identify challenges to retaining top- and middle-level managers and (b) to identify strategies to retain them as perceived by senior HR professionals.

The EFA resulted in a five-factor solution: three retention challenges and two retention strategies. A lack of attention to employee wellbeing, a poor work environment and an organisational context characterised by outdated technologies, traditional hierarchies and affirmative action strategies were viewed as challenges in retaining top and middle-level managers. Performance management and leadership were regarded by HR professionals as retention strategies. In sum, the challenges and retention strategies identified by HR professionals applied to both top- and middle-level managers but applied to a greater extent to middle-level managers.

\section{Retention challenges}

HR professionals perceive that a challenge to retaining topand middle-level managers exists if there is a disregard for employee wellbeing within the organisation. Such disregard is evidenced by a lack of assistance from the HR department in assisting managers in dealing with personal problems and a lack of concern by both HR professionals and line managers for personal welfare of staff. Van Dyk and Coetzee (2012) note how concern for employee wellbeing reduces stress. Similarly, a lack of concern for employees and an absence of 
recognition of work-life balance negatively impacts employee commitment levels and stimulates turnover intention (Deery 2008; Yarnall 2011).

The work environment presents a challenge in retaining managers. Extreme workloads, lack of challenging work, a lack of workforce diversity and a lack of employment engagement all contribute to the work environment challenge. Devi (2009) notes the effect of a poor work environment that translates into reduced motivational levels, employee disengagement and a resultant decline in employee performance. Doh et al. (2011) suggest that being required to undertake boring and meaningless work leads to intent to leave and Monsen and Boss (2009) note that the setting of unrealistic performance goals results in role ambiguity and internal conflict between managers and their direct reports.

Organisational contextual factors were noted by HR professionals to present a retention challenge. The practices here involved working in traditional hierarchies, working with outdated technology and dealing with the array of affirmative action strategies requiring adherence to by organisations. White (2010) observes that micromanagerial style results in a decrease of job satisfaction with attendant high turnover rates. Khoele and Daya (2014) suggest that affirmative action strategies can cause frustration in nonaffirmative action candidates because career expectations may be thwarted.

\section{Retention strategies}

Performance management appears to be a strategy to retain managers. Within the ambit of performance management, HR professionals identified the following retention strategies: the recognition for the achievement of developmental goals, the provision of quality developmental or training opportunities, the setting of realistic targets, the institution of meaningful, tailored rewards, the collaborative determination of developmental needs and rewards for meeting targets. Mda (2010) argues that top managers, in particular, are more attracted to intrinsic rewards because of their intellectual status and experience in the field and that they tend to have more of a need for achievement rather than for material rewards. Kim and Lee (2007) note that, over time, as managers develop themselves and their careers, they begin to evidence more interests in intrinsic rewards. Intrinsic rewards are known to be more fulfilling to top-level managers and contribute to their sense of purpose in the organisation (Hausknecht et al. 2009). Providing employees with developmental opportunities to enrich career growth serves to reinforce the psychological contract that employees hold towards the organisation (De Vos \& Meganck 2008).

Leadership of the organisation is an important retention strategy. In fact, effective HR practices are directly affected by leaders (Lawler 2008). Leadership involves trust and communication between line managers and direct reports, appreciation and support by line managers, leadership style and ethical leadership. Lawler (2008) suggests that leaders who follow a more liberal and servant-like leadership style tend to have better relationships with employees. Leaders are also responsible for developing clear and strong visions for their organisations (Yarnall 2011) which, in turn, impacts the meaningfulness of work and promotes intellectual stimulation (Doh et al. 2011). Trust between line managers and direct reports tends to play an important role in the retention of managers (Chun et al. 2013) and trust underlies the concept of ethical leadership (Avey et al. 2012).

\section{Practical implications}

HR professionals should appreciate the challenges to retention, particularly for middle managers. These challenges relate to addressing employee wellbeing, the work environment and the organisational context. HR professionals should also understand that targeted strategies focusing on leadership and performance management can assist in retaining top- and middle-level managers, more specifically the former. In this regard, HR professionals should assist line managers in developing communication and trust with their direct reports, in appreciating their work and supporting them in their work activities, promoting ethical leadership within the organisation.

\section{Limitations}

The findings are based on the perceptions of HR professionals regarding effective retention strategies for top- and middlelevel managers. Such perceptions may be subjective. Secondly, the response rate was considered adequate for the data analysis. However, a higher response rate could, perhaps, have been achieved through the use of a survey method other than an online questionnaire, which may have appeared impersonal in an email. Accordingly, the findings cannot be generalised to a larger population.

\section{Suggestions for future research}

While the challenges and strategies identified applied to both top- and middle-level managers, they were statistically more relevant to middle-level managers. It is recommended that a similar study that focuses on the challenges faced in retaining top-level managers be undertaken to provide greater insight into this group.

It is further recommended that a similar study be conducted into the perceptions of top- and middle-level managers to enable these managers, themselves, to identify the challenges they face and the retention strategies that they would consider relevant. This study was South Africa specific and future research could focus on exploring effective retention strategies utilised by $\mathrm{HR}$ professionals in international contexts. The findings of this study are drawn from the perceptions of HR professionals working in various South African industries. A study that segments industries could provide HR professionals with industry-specific retention strategies that are likely to be more effective (Hausknecht et al. 2009). 


\section{Conclusion}

Retaining senior talent presents a challenge to organisations (Guthridge et al. 2008), especially in the context of globalisation and ease of job mobility (Cappelli 2008). Accordingly, it is important that HR professionals understand the challenges presented in retaining top talent and focus, particularly, on talent retention strategies.

\section{Acknowledgements}

We thank Ms Jaclyn de Klerk (Statistical Consultation Services at the University of Johannesburg) for assisting with the creation of the online questionnaire, as well as for the statistical analysis. We also thank the SABPP for their permission and access to the registered members of the professional body and their willingness to assist with the distribution of the online questionnaire.

\section{Competing interests}

The authors declare that they have no financial or personal relationships that may have inappropriately influenced them in writing this article. This study was based on a Master's study conducted in the Department of Industrial Psychology and People Management at the University of Johannesburg.

\section{Authors' contributions}

D.U. was responsible for the conceptualisation of the project and conducted the fieldwork in fulfilment of the requirements for her MCom (Human Resources Management) degree. P.C.-F. and A.T. were her supervisor and co-supervisor, respectively, and made conceptual contributions. All three authors were involved in writing the literature review, data interpretation, conclusions and recommendations.

\section{References}

Abdi, H. \& Williams, L.J., 2010, 'Principal component analysis', Computational Statistics 2(1), 433-470. https://doi.org/10.1002/wics.101

Allen, D.G. \& Bryant, C.P., 2012, Managing employee turnover: Dispelling myths and fostering evidence-based retention strategies, Business Expert Press, New York.

Ashton, C. \& Morton, L., 2005, 'Managing talent for competitive advantage: Taking a systemic approach to talent management', Performance Improvement Solution 4(5), 28-31. https://doi.org/10.1108/14754390580000819

Avey, J.B., Wernsing, T.S. \& Palanski, M.E., 2012, 'Exploring the process of ethical leadership: The mediating role of employee voice and psychological ownership' Journal of Business Ethics 107(1), 21-34. https://doi.org/10.1007/s10551-012 1298-2

Bandalos, D.L. \& Finney, S.J., 2010, 'Factor analysis: Exploratory and confirmatory', in G.R. Hancock \& R.O. Mueller (eds.), The reviewer's guide to quantitative methods in the social sciences, pp. 93-114, Routledge, New York.

Beaumont, R., 2012, 'An introduction to principal component analysis and facto analysis using SPSS 19 and R (psych package)', viewed 05 April 2017, from http:// www.floppybunny.org/robin/web/virtualclassroom/stats/statistics2/pca1.pdf

Bhatnagar, J., 2007, 'Talent management strategy of employee engagement in Indian ITES employees: Key to retention', Employee Relations 29(6), 640-663. https:// doi.org/10.1108/01425450710826122

Cappelli, P., 2008, 'Talent management for the twenty-first century', Harvard Business Review 86(3), 1-9. https://doi.org/10.1225/R0803E

Chun, J.S., Shin, Y., Choi, J.N. \& Kim, M.S., 2013, 'How does corporate ethics contribute to firm financial performance? The mediating role of collective organizational commitment and organizational citizenship behavior', Journal of Management 39(4), 853-877. https://doi.org/10.1177/0149206311419662

Cohen, J., 1988, Statistical power analysis for the behavioral sciences, 2nd edn., L. Erlbaum Associates, Hillsdale, NJ.
Cook, C. \& Thomson, B., 2000, 'Higher-order factor analysis as a score validity evaluation tool: An example with a measure of perceptions of library service setting', viewed 05 April 2017, from http://www.eric.ed.gov/contentdelivery/ setting, viewed 05 April 2017, from
servlet/ERICServlet?accno=ED438312

Cosack, S., Guthridge, M. \& Lawson, E., 2010, 'Retaining key employees in times of change', The McKinsey Quarterly 3(1), 135-139.

Deery, M., 2008, 'Talent management, work-life balance and retention strategies', International Journal of Contemporary Hospitality Management 20(7), 792-806. https://doi.org/10.1108/09596110810897619

Department of Higher Education and Training, 2016, List of occupations in high demand: 2015. Government Gazette 39604, Pretoria.

Devi, V.R., 2009, 'Employee engagement is a two-way street', Human Resource Management International Digest 17(2), 3-4. https://doi.org/10.1108/096707 30910940186

De Vos, A. \& Meganck, A., 2008, 'What HR managers do versus what employees value: Exploring both parties' views on retention management from a psychological contract perspective', Personnel Review 38(1), 45-60. https://doi.org/10.1108/ 00483480910920705

Döckel, A., Basson, J.S. \& Coetzee, M., 2006, 'The effect of retention factors on organisational commitment: An investigation of high technology employees', South African Journal of Human Resource Management 4(2), 20-28. https://doi. org/10.4102/sajhrm.v4i2.91

Doh, J.P., Smith, R.R., Stumpf, S.A. \& Tymon, W.G.J., 2011, 'Pride and professionals: Retaining talent in emerging economies', Journal of Business Strategy 32(5), 3542. https://doi.org/10.1108/02756661111165453

Edwards, J.R. \& Cable, D.M., 2009, 'The value of value congruence', The Journal of Applied Psychology 94(3), 654-677. https://doi.org/10.1037/a0014891

Farndale, E., Scullion, H. \& Sparrow, P., 2010, 'The role of the corporate HR function in global talent management', Journal of World Business 45(2), 161-168. https://doi. org/10.1016/j.jwb.2009.09.012

Gelo, O., Braakmann, D. \& Benetka, G., 2008, 'Quantitative and qualitative research: Beyond the debate', Integrative Psychological and Behavioral Science 42(1), 266290. https://doi.org/10.1007/s12124-008-9078-3

Govaerts, N., Kyndt, E., Dochy, F. \& Baert, H., 2011, 'Influence of learning and working climate on the retention of talented employees', Journal Workplace Learning 23(1), 35-55. https://doi.org/10.1108/13665621111097245

Guest, D.E. \& Conway, N., 2011, 'The impact of HR practices, HR effectiveness and a "strong HR system" on organisational outcomes: A stakeholder perspective', The International Journal of Human Resource Management 22(8), 1686-1702. https:// doi.org/10.1080/09585192.2011.565657

Guthridge, M. \& Komm, A.B., 2008. 'Why multinationals struggle to manage talent', The McKinsey Quarterly 4, 10-13.

Guthridge, M., Komm, A.B. \& Lawson, E., 2008, 'Making talent a strategic priority', The McKinsey Quarterly 48(1), 49-59.

Hausknecht, J.P., Rodda, J. \& Howard, M.J., 2009, 'Targeted employee retention, performance-based and job-related differences in reported reasons for staying', Human Resource Management 48(2), 269-288. https://doi.org/ staying, Human

IBM Corp, 2015, Released 2015. IBM SPSS Statistics for Windows, Version 23.0, IBM Corp., Armonk, NY

Iles, P., Chuai, X. \& Preece, D., 2010, 'Talent management and HRM in multinational companies in Beijing: Definitions, differences and drivers', Journal of World Business 45(2), 179-189. https://doi.org/10.1016/j.jwb.2009.09.014

Jaaskelainen, A., 2011, 'How to measure and manage the risk of losing key employees?', International Journal of Learning and Intellectual Capital 8(1), 6375. https://doi.org/10.1504/IJLIC.2011.037359

Kerr-Phillips, B. \& Thomas, A., 2009, 'Macro and micro challenges for talent retention in South Africa', SA Journal of Human Resource Management 7(1), 82-91. https:// doi.org/10.4102/sajhrm.v7i1.157

Khoele, A. \& Daya, P., 2014, 'Investigating the turnover of middle and senior managers in the pharmaceutical industry in South Africa', SA Journal of Human Resource Management 12(1), 1-10. https://doi.org/10.4102/sajhrm.v12i1.562

Kim, S.E. \& Lee, J.W., 2007, 'Is mission attachment an effective management tool for employee retention? An empirical analysis of a nonprofit human services agency', Review of Public Personnel Administration 27(3), 227-248. https://doi. org/10.1177/0734371X06295791

Ladyshewsky, R.K., 2010, 'The manager as coach as a driver of organizational development', Leadership \& Organization Development Journal 31(4), 292-306. https://doi.org/10.1108/01437731011043320

Lawler, E.E., 2008, 'Why are we losing all our good people?', Harvard Business Review $86(6), 2-10$.

Letchmiah, L. \& Thomas, A., 2017, 'Retention of high-potential employees in a development finance company', SA Journal of Human Resource Management 15(0), 1-9. https://doi.org/10.4102/sajhrm.v15i0.924

Marshall, C. \& Rossman, G.B., 1999, Designing qualitative research, 3rd edn., Sage, Thousand Oaks, CA.

McDonnell, A., Lamare, R., Gunnigle, P. \& Lavelle, J., 2010, 'Developing tomorrow's leaders: Evidence of global talent management in multinational enterprises', Journal of World Business 45(2), 150-160. https://doi.org/10.1016/j.jwb.2009. 09.015

Mda, A.M., 2010, 'Staff turnover in the Information and Communication Technology (ICT) sector in South Africa', PhD thesis, Scripps College of Communication, Ohio University. 
Menz, M., 2012, 'Functional top management team members: A review, synthesis, and research agenda', Journal of Management 38(1), 45-80. https://doi. and research agenda', Journal
org $/ 10.1177 / 0149206311421830$

Monsen, E. \& Boss, R.W., 2009, 'The impact of strategic entrepreneurship inside the organization: Examining job stress and employee retention', Entrepreneurship, Theory and Practice 33(1), 71-104. https://doi.org/10.1111/j.1540-6520.2008. 00281.x

Nunnally, J.C., 1978, Psychometric theory, 2nd edn., McGraw-Hill, New York.

Ramsey, F.L. \& Schafer, D.W., 2013, The statistical sleuth: A course in methods of data analysis, 3rd edn., Brooks/Cole, Cengage Learning, Boston, MA.

Razali, N.M. \& Wah, Y.B., 2011, 'Power comparisons of Shapiro-Wilk, Kolmogorov Smirnov, Lilliefors and Anderson-Darling tests', Journal of Statistical Modeling and Analytics 2(1), 21-33.

StatsSA, 2016, Community survey 2016: Statistical release P0301, Statistics South Africa, Pretoria.

Tabachnick, B.G. \& Fidell, L.S., 2014, Using multivariate statistics, 6th edn., Pearson Education Limited, Harlow, UK.

Tansley, C., 2011, 'What do we mean by the term "talent" in talent management?', Industrial and Commercial Training 43(5), 266-274. https://doi.org/10.1108/ 00197851111145853

Tarique, I. \& Schuler, R.S., 2010, 'Global talent management: Literature review, integrative framework, and suggestions for further research', Journal of World Business 45(2), 122-133. https://doi.org/10.1016/j.jwb.2009.09.019
Tymon, W.G., Stumpf, S.A. \& Doh, J.P., 2010, 'Exploring talent management in India: The neglected role of intrinsic rewards', Journal of World Business 45(2), 109-121. https://doi.org/10.1016/j.jwb.2009.09.016

Van Dyk, J. \& Coetzee, M., 2012, 'Retention factors in relation to organisational commitment in medical and information technology services', SA Journal of Human Resource Management 10(2), 1-12. https://doi.org/10.4102/sajhrm. v10i2.433

Wagar, T.H. \& Rondeau, K.V., 2006, 'Retaining employees in small and medium-sized firms: Examining the link with human resource management', Journal of Applied Management and Entrepreneurship 11(2), 3-16.

White, R.D., 2010, 'The micromanagement disease: Symptoms, diagnosis and cure', Public Personnel Management 39(1), 71-76. https://doi.org/10.1177/0091026 01003900105

Williams, B., Brown, T. \& Onsman, A., 2012, 'Exploratory factor analysis: A five-step guide for novices', Australasian Journal of Paramedicine 8(3), 1-13. https://doi. org/10.1136/emj.2010.091751

Wind, Y., Green, P.E. \& Jain, A.K., 1973, 'Higher order factor analysis in the classification of psychographic variables', Journal of the Market Research Society 15(4), 224-232.

Yarnall, J., 2011, 'Maximising the effectiveness of talent pools: A review of case study literature', Leadership and Organizational Development Journal 32(5), 510-526. https://doi.org/10.1108/01437731111146596 